\title{
Experience Of Resident Presentations In Consultation-Liaison Psychiatry Grand Rounds: Increase Value For Clinical Education
}

This article was published in the following Dove Press journal: Advances in Medical Education and Practice

\section{Edwin S Meresh (D) \\ David Daniels \\ Murali Rao (D) \\ Aparna Sharma (iD \\ Angelos Halaris \\ David Schilling (D)}

Department of Psychiatry, Loyola University Medical Center, Maywood, IL 60I53, USA
Correspondence: Edwin S Meresh Department of Psychiatry, Loyola University Medical Center, 2160 S. First

Ave, Maywood, IL 60I53, USA

Tel + I 7082163274

Email Emeresh@lumc.edu
Background: Grand rounds is a formal meeting at which physicians and trainees discuss excellence in medical care. Residents should participate in scholarly activity per Accreditation Council for Graduate Medical Education (ACGME). Consultation-Liaison (CL) psychiatry focuses on caring for patients presenting with psychiatric complications in general hospital. Post-residency subspecialty CL fellowship training plays a big role in creating future leaders in CL. Our program decided to conduct annual CL grand rounds fully allotted to discuss complex CL psychiatry cases in medical setting.

Methods: We conducted a retrospective review of resident's interest in pursuing CL fellowship. We compared the number of residents pursuing CL fellowship after the CL grand rounds to the previous years starting 2005 when CL was recognized as an ACGME approved subspecialty. We also compared our program residents pursuing CL psychiatry fellowship to national trend obtained from National Residency Matching Program (NRMP).

Results: From 2013 to 2018, CL grand rounds $n=8$, Number of residents graduated from 2013 to $2018 \mathrm{n}=26$. Number of residents pursued CL fellowship from 2013 to $2018 \mathrm{n}=3$ (11.5\%) compared to no residents pursuing CL fellowship before 2013. Fisher's exact test to compare and examine the data from the residents pursuing CL fellowship after implementation of the CL grand rounds is 0.0668 ( $\mathrm{p}$ value $<0.10$ ). When combining all the available NRMP match results for CL from 2015 to 2019, a total of 531 positions were offered and 359 positions were filled (fill rate of $67.6 \%$ ). In our program, after we implemented the annual CL grand rounds, $11.5 \%$ of the residents from 2013 to 2018 pursued CL fellowship, which is higher than the likely national average of $5.7 \%$.

Conclusion: Our residency program grand rounds educational module appears to nurture and sustain interest in CL subspecialty compared to previous years. Prospective studies are required. Keywords: Consultation-Liaison psychiatry, residents, grand rounds, case presentations, fellowship

\section{Background}

Grand rounds is a formal meeting at which physicians and trainees discuss excellence in medical care or recent medical advances. ${ }^{1}$ Grand rounds originated as part of residency training and play a key role in graduate medical education. ${ }^{2}$ They present clinical problems in medicine by focusing on current or interesting cases. They are also sometimes utilized for dissemination of new research information. ${ }^{3}$ Grand rounds is open to the whole department and even open to whole medical center, faculty, residents and other staff (audience 50 to 100). Attendance for the 
department is mandatory. An outside speaker or an internal faculty present during grand rounds. Other reports mention that grand rounds is a stage where eminent scholars demonstrated their skills to the audience or Specialists interacted and debated ideas. ${ }^{4,5}$ Occasionally, an individual resident, a group of residents or residents and faculty present during grand rounds. While its popularity may have decreased, grand rounds is still considered very important in many teaching hospitals. ${ }^{6}$ This study has identified opportunities for improving grand rounds. ${ }^{7}$

One program reported on a resident grand rounds series. ${ }^{8}$ Morbidity \& Mortality (M\&M) rounds is reporting and analysis of adverse events and follow-up education in evidencebased practice. ${ }^{9,10} \mathrm{M} \& \mathrm{M}$ conferences in psychiatry are limited. ${ }^{11}$ There is a need for the psychiatric services in organizing M\&M conferences ${ }^{12}$ Quality improvement training in psychiatry residency is feasible. ${ }^{13}$ Consultation-Liaison (CL) psychiatry focuses on caring for patients presenting with psychiatric complications in general hospital. Medically complex patients in general hospital setting present with physical, mental, social and health system difficulties. ${ }^{14}$ Subspecialty CL fellowship training after completion of psychiatry residency plays a big role in creating future leaders in CL. Given that residents should participate in scholarly activity per Accreditation Council for Graduate Medical Education (ACGME) ${ }^{15}$ one might expect that residents would participate in grand rounds as a scholarly activity experience. However, this could not be confirmed, as there are limited reports on psychiatry department grand rounds. ${ }^{16-20}$ As such, we were not able to identify any report on regular CL psychiatry resident grand rounds.

Grand rounds in our program at Loyola University Medical Center is conducted weekly from September to June and typically is a presentation by a regionally or nationally known expert who presents topics related to psychiatry. A few grand rounds each year are presentations by the medical center faculty. As part of their scholarly activity, 4th-year psychiatry residents present their topic of interest during psychiatry grand rounds. In addition, residents of any year pair with an attending and together present during psychiatry grand rounds. In 2007, we started a bi-weekly psychiatry department CL case conference where medical students and residents present cases. After the module began, there was an increase in the number of students pursuing psychiatry residency. ${ }^{21}$ In contrast to a grand rounds, the case conference audience is smaller (around 20 to 30), and departmental attendance is not mandatory. In the years following the creation of the
CL psychiatry case conference, a few residents presented $\mathrm{CL}$ topic along with the $\mathrm{CL}$ attending during grand rounds. This led to a demand for a separate annual CL grand rounds that would discuss complex CL cases. Based on the success of our bi-weekly case conference, the department chair, the residency program director, and the residency program evaluation committee all approved the request for a grand rounds slot yearly for CL case discussion.

In 2013, what became an annual CL grand rounds event began. Under faculty guidance, a team of residents presented complex cases seen in general hospital setting diagnosed with psychiatric complications. Cases and topics were identified for CL grand rounds during their 2nd-year resident CL rotation, and they presented during their 3rd year. A team of 3rd-year residents, sometimes accompanied by a 2nd-year resident or senior 4th-year resident, mainly did the presentations. While some issues might be covered, that overlapped what would happen in an $\mathrm{M} \& \mathrm{M}$ case conference or a risk management review, this was not an M\&M case conference nor a risk management review. All presenting topics were primarily management related to psychiatric complications in general medical setting. Few cases of superior complexity were selected for CL grand rounds. Institutional Board Approval (IRB) is not applicable as these are not research patients. In order to assure patient privacy and confidentiality, patients were de-identified in the presentation of the patient history from the medical record. Patients were not audio or video taped nor were patients present during the grand rounds presentation. Furthermore, a written form of the case presentation was not provided to the faculty and trainee audience. The primary purpose of the grand rounds was to enhance knowledge and generate feedback on the management of psychiatric complications in general medical setting.

\section{Format And Structure Of Presentation}

Powerpoint presentation was used in the grand rounds presentation with each involved resident leading a different section of the presentation. The format and structure of presentation in all eight presentations were identical in structure. The order the presentation typically followed was: Patient's presenting history, Past medical history and laboratory findings; Mental status examination; Differential diagnosis and diagnosis; Management; Response to treatment; Patient 
progress and outcome. For the patient management section of the presentation, a literature search was conducted to investigate what the literature indicate about the treatment that had been chosen. Finally, the audience was provided an opportunity to discuss their questions with the presenters.

\section{Methods}

We conducted a retrospective review of resident's interest in pursuing CL fellowship. Program evaluation committee look into number of residents pursuing subspecialty training. To rectify any deficiency, CL division, residency program evaluation committee, department chair, and residency program director wanted to see if the establishment of CL grand rounds has led to strengthening of the CL rotation and residents pursuing CL fellowship. We compared the number of residents pursuing CL fellowship after establishment of the CL grand rounds to the previous years starting 2005 when CL was recognized as an ACGME approved subspecialty. The Psychiatry Residency Program director provided data. Data analyzed were the number of residents presented during grand rounds, number of residents graduated from psychiatry residency, and number of residents who pursued CL fellowship.

We also compared our program residents pursuing CL psychiatry fellowship to national trend obtained from National Residency Matching Program (NRMP).

CL Supervisor grade before and after CL grand rounds was compared.

\section{Results}

From 2008 to 2012, Psychiatry department grand rounds conducted by the CL service with residents and CL attending presenting $\mathrm{CL}$ related topics and cases $n=8$, 2nd-year residents $n=4$, 3rd-year residents $n=1$, 4th-year residents $n=4$

From 2013 to 2018 , CL grand rounds $n=8,19$ residents presented on the following topics

1. Melatonin for Delirium (2013)

2. Intravenous Valproic Acid for Agitation Management (2013)

3. Bilateral Globus Pallidus Infarction With Heroin Overdose (2013)

4. Gabapentin for Alcohol Withdrawal in Patients with Hepatic Encephalopathy: Case Series Report and Literature Review (2014)

5. Neuropsychiatric Sequelae of Hypoglycemic Coma (2015)
6. Quetiapine and Valproate for Re-emerging Psychosis in Catatonia - Case Series Report (2016)

7. Dopamine D2 Receptor Agonists, Antagonists, and Glutamate Modulators in Neuroprotection - Case Series Report (2017)

8. New Frontiers in the Management of Agitation in the General Hospital (2018)

4th-year residents $n=4$, 3rd-year residents $n=13$, 2nd-year residents $n=2$, 1 st-year residents $n=0$

Number of residents graduated from 2013 to $2018 n=26$

Number of residents from 2013 to 2018 pursued CL fellowship $(n=3)(11.5 \%)$ compared to no residents pursuing CL fellowship before 2013 going back to 2005 when CL was recognized as an ACGME approved subspecialty.

Number of residents graduated from 2005 to 2012 $(n=41)$. Number of residents pursued CL fellowship from 2005 to $2012(\mathrm{n}=0)$ (Table 1$)$.

We used Fisher's exact test to compare and examine the data from the residents pursuing CL fellowship after implementation of the CL grand rounds. After implementation of the CL grand rounds, we saw residents pursuing CL fellowship. Fisher's exact test to compare and examine the data from the residents pursuing CL fellowship after implementation of the CL grand rounds is 0.0668 ( $\mathrm{p}$ value $<0.10$ ), indicating a trend towards resident pursuing CL fellowship after implementation of CL grand rounds.

In the 2019 National Residency Matching Program (NRMP) match result for CL psychiatry fellowship, 26 of the 58 programs were unfilled; of the 119 positions offered, 37 positions were unfilled $(31 \%){ }^{22}$ On the other hand, for general psychiatry residency, 298 programs offered 1740 positions and $98.9 \%$ were filled. $^{23}$

Per 2017 NRMP match result statistics for CL psychiatry fellowship, $46.2 \%$ of the fellowship programs went unfilled. $^{15}$ This number further increased to $48.2 \%$ per 2018 NRMP match result. ${ }^{22}$

In 2013 general psychiatry residency match, 231 programs offered 1360 positions $^{24}$ and as these residents approached graduation after their 4 years training, in

Table I Graduating Residents Pursuing CL Fellowship

\begin{tabular}{|l|l|l|}
\hline & $\begin{array}{l}\text { No Of Residents } \\
\text { Graduated }\end{array}$ & $\begin{array}{l}\text { No Of Residents } \\
\text { Pursuing CL Fellowship }\end{array}$ \\
\hline 2005 to 2012 & 41 & 0 \\
2013 to 2018 & 26 & $3(11.5 \%)$ \\
\hline
\end{tabular}


2017, for 2017 CL match results, only 70 positions were filled which comes to a rough estimate of $5 \%$.

In 2014 psychiatry residency match, 203 programs offered 1322 positions ${ }^{25}$ and these residents graduating in 2018, 2018 CL match results, again, 70 positions that comes to around $5 \%$.

When considering all the available match results for $\mathrm{CL}$ from 2015 to 2019,359 positions were filled. ${ }^{22}$ From 2011 to 2015, 6250 general psychiatry residency positions were offered. ${ }^{24-28}$ Psychiatry residency is 4 years and considering 2011 first-year psychiatry residents applied during their final year in 2015 and matched into 2015 CL fellowship, 5.7\% of the residents roughly pursued CL fellowship.

Residents every year evaluate the CL rotation and the CL rotation supervisor who is also in charge of conducting the CL grand rounds. Resident evaluations grading the CL rotation supervisor- 2010-2013 average was 2.875/3 and 2014-2018 average increased to $2.99 / 3$ after CL grand rounds.

Below are a few residents' statements mentioned in the evaluation form commenting about the CL supervisor and CL rotation experience:

Continue to provide articles and study materials for residents, these were very helpful and promoted a healthy learning environment.

He supplied articles that I have found useful both on my current and future rotations.

Thoroughly enjoyed this rotation and considered it to be the most valuable rotation of my residency career.

By far the best rotation thus far

I have learned a lot about evidence-based practices from him, and I really appreciate that.

Provide invaluable input on difficult cases

I have learned a great deal from his pre-rounds and the different interesting cases we saw during CL.

\section{Discussion}

In our program, CL rotation is during the second year. From 2013, most of the CL grand rounds presentations by residents were during the 3rd year of residency as a team after they completed their 2nd-year CL rotation, but all the cases presented were seen and selected during their previous 2nd-year CL rotation. A few CL cases and topics were presented between 2008 and 2012. When CL service was invited for grand rounds, the clinical experience that led to the presenting resident's topic or case had taken place just a few months earlier. From 2008 to 2012, there was less opportunity for longitudinal discussion and preparation. However, from 2013 to 2018, most of the presentations done by the 3rd-year residents were from clinical experiences that had taken place during their previous 2 nd-year CL experience. This allowed for sufficient time for discussions, literature search, and preparations. This resulted in an ongoing learning experience for the residents. The difference between the presentations from 2008 to 2012 versus 2013 to 2018 is that in the former, cases and topics were selected quickly. In the latter, cases and article reviews were selected further in advance. The main difference between the two resident groups is the additional time for the latter group allowed for an ongoing longitudinal learning experience.

In our program, for years (2005 to 2012), no residents pursued CL fellowship. As the curriculum was strengthened with the creation of the CL case conference and CL grand rounds, residents were provided with broader CL educational activities. For programs where historically no residents pursue CL fellowship, our model could be applicable to strengthen CL curriculum and possibly lead to residents pursuing CL fellowship. Program evaluation committee among many variables (board passing rate, publishing papers, etc.) also look into number of residents pursuing subspecialty training after graduation and before going for job. Any deficiency in training needs to be rectified and CL grand round could lead to positive outcome including strengthening of the CL rotation and residents pursuing CL fellowship. Resident evaluation of the $\mathrm{CL}$ rotation experience and supervisor grading improved further and as the major addition to the CL curriculum was the annual CL grand rounds, it is likely that the CL grand rounds preparation overall made an impact for resident's learning experience and their perception on CL rotation.

Psychiatry residency is 4 years training. Three CL faculty are in our division. Our institution does not offer CL fellowship. Residents go to CL fellowship to other programs. A small number of residents from our program pursued CL fellowship. Multiple CL fellowship positions remain unfilled. Fellows could be the future leaders of that subspecialty. There certainly are programs (with strengths in CL) were few to many residents likely go on to pursue CL fellowship. Are all the CL fellows coming from a small number of residency programs? It could also be that the fellows are coming from a broader number of programs. Considering the fact that there are 235 psychiatry residency programs in the USA to fill the 119 positions, it is then likely that residents from fewer programs are considering CL fellowship. It is also likely that for years, graduates from many psychiatry residency programs did 
not and continue to not pursue CL fellowship. Only a survey given to all the residency programs directly could likely answer that question.

Residents choose to go to a particular fellowship for various reasons. A module like annual CL grand rounds could keep that interest sustained so that the resident will not lose interest in that particular field as they approach graduation. What the resident does in preparing for the $\mathrm{CL}$ grand rounds with their research into the literature about the diagnosis and treatment is what a CL psychiatrist has to do with some regularity as part of their job. This may help residents better understand what being a CL psychiatrist is like and help clarify and focus the interest of residents who are so inclined. Importantly, this grand rounds educational activity is a great learning experience and it improves knowledge.

\section{Limitations}

There are limitations to our report. We have not conducted a prospective survey. Residents evaluate the CL rotation and the CL supervisor after they complete the CL rotation. Since the CL grand rounds are held well after the resident completes the CL rotation, the resident's evaluation does not necessarily reflect the grand rounds experience. It may, however, reflect the resident's preparation for the grand rounds. Because residents from 2013 and following years have graduated, it has not been feasible to conduct a survey about their CL grand rounds experience fostering interest in CL psychiatry. Survey of residents in CL psychiatry at the following times: before the resident did the CL rotation, immediately after the resident completed the $\mathrm{CL}$ rotation, and then immediately after the CL grand rounds might help better answer the question if CL grand rounds stimulate interest in CL psychiatry. Survey also could address the number of CL faculty and the impact on stimulating CL interest.

During CL rotation, resident interacts with multiple specialties including internal medicine, general surgery, critical care, neurology, neurosurgery, rehabilitation, pain, addiction, legal, and transplant. These are additional aspects likely add to foster interest in CL psychiatry. The national average of $5.7 \%$ residents pursuing CL fellowship is a rough estimate, derived from the total number of positions offered for the first year.

\section{Conclusion}

A small number of residents from our program pursued CL fellowship. Prospective studies are needed to see if one grand rounds per year allotted to CL psychiatry for residents lead to interest in that subspecialty so that interest in subspecialty could be developed and sustained. Grand rounds presentation for residents yearly is feasible and has broader outcomes including discussions, mentorship, preparations, and literature review. Resident grand rounds and the related educational activities could promote interest in fellowship and sustain that interest in pursuing fellowship. When the residents complete their CL rotation, they have seen and managed complex cases but they are not completely done with their CL learning. The preparation for CL grand rounds offers them an ongoing learning experience that is consistent with the longitudinal educational model. Our resident grand rounds educational module in our program appears to nurture and sustain interest in CL subspecialty compared to previous years. To our knowledge, this is the first report of CL psychiatry resident grand rounds experience.

\section{Disclosure}

The authors report no conflicts of interest in this work.

\section{References}

1. Lewkonia RM, Murray FR. Grand rounds: a paradox in medical education. CMAJ. 1995;152(3):371-376.

2. Herbert R, Wright SM. Re-examining the value of medical grand rounds. Acad Med. 2003;78(12):1248-1252. doi:10.1097/00001888200312000-00013

3. Sandal S, Iannuzzi MC, Knohl SJ. Can we make grand rounds "grand" again? J Grad Med Educ. 2013;5(4):560-563. doi:10.4300/ JGME-D-12-00355.1

4. Stanyon M, Khan SA. Requiem for the grand round. Clin Med (Lond). 2015;15(1):10-11. doi:10.7861/clinmedicine.15-1-10

5. Dolcourt JL, Zuckerman G, Warner K. Learners' decisions for attending Pediatric Grand Rounds: a qualitative and quantitative study. BMC Med Educ. 2006;6:26. doi:10.1186/1472-6920-6-26

6. Parrino TA, White AT. Grand rounds revisited: results of a survey of U.S. Departments of Medicine. Am J Med. 1990;89(4):491-495. doi:10.1016/0002-9343(90)90381-m

7. Van Hoof TJ, Monson RJ, Majdalany GT, Giannotti TE, Meehan TP. A case study of medical grand rounds: are we using effective methods? Acad Med. 2009;84(8):1144-1151. doi:10.1097/ACM.0b013e3181ad1c0e

8. Wasser T, Ross DA. Resident grand rounds. Med Educ. 2016;50 (11):1157-1158. doi:10.1111/medu.13193

9. Goldman S, Demaso DR, Kemler B. Psychiatry morbidity and mortality rounds: implementation and impact. Acad Psychiatry. 2009;33:383-388. doi:10.1176/appi.ap.33.5.383

10. Orlander JD, Fincke BG. Morbidity and mortality conference: a survey of academic internal medicine departments. J Gen Intern Med. 2003;18:656-665. doi:10.1046/j.1525-1497.2003.20824.x

11. Wasser T, Grunschel BD, Stevens A, et al. Transforming systems of care through a novel resident-led approach to morbidity and mortality conferences. Acad Psychiatry. 2016;40(6):893-897. doi:10.1007/ s40596-016-0606-z

12. Hollanda J. A role for morbidity and mortality conferences in psychiatry. Australas Psychiatry. 2007;15(4):338-342. doi:10.1080/ 10398560701351803 
13. Arbuckle MR, Weinberg M, Cabaniss DL, et al. Training psychiatry residents in quality improvement: an integrated. Year Long Curriculum Acad Psychiatr. 2013;37:42-45. CrossRefGoogleScholar. doi:10.1176/ appi.ap. 11120214

14. Kathol RG, Kunkel EJ, Weiner JS, et al. Psychiatrists for medically complex patients: bringing value at the physical health and mental health/substance-use disorder interface. Psychosomatics. 2009;50 (2):93-107. doi:10.1176/appi.psy.50.2.93

15. Accreditation Council for Graduate Medical Education. Resident's Scholarly Activity. Available from: https:/www.acgme.org/Portals/ 0/PFAssets/ProgramRequirements/CPRs_2017-07-01.pdf. Accessed October 12, 2019, Page 12.

16. Kunik ME, Merritt SG, Dahlquist LM, Marks D. Correlates of psychiatry grand rounds attendance. Acad Psychiatry. 1993;17 (2):77-83. doi:10.1007/BF03341858

17. Jain $\mathrm{S}$. Where are the women academic speakers at psychiatry grand rounds? Acad Psychiatry. 2005;29(3):322. doi:10.1176/appi.ap.29.3.322

18. Ramchandani D. Usefulness of psychiatric grand rounds for medical student education. Acad Psychiatry. 2009;33(2):149-151. doi:10.1176/ appi.ap.33.2.149

19. Qadri SF, Hill E, Madison J, Ramaswamy S. Successfully implementing schwartz center rounds within an adult psychiatric hospital. Acad Psychiatry. 2017;41(1):118-120. doi:10.1007/s40596-016-0506-2

20. Park G, Prabhakar D. Inviting police officers to grand rounds. Acad Psychiatry. 2016;40(1):194-195. doi:10.1007/s40596-015-0472-0

21. Meresh E, Rao M, Schilling D, Niedzwiecki M, Halaris A. Medical students' interest in pursuing psychiatry residency: a 5-year analysis of a consultation psychiatry clerkship educational module. Acad Psychiatry. 2014;38(1):104-105. doi:10.1007/s40596-013-0013-7

22. National Resident Matching Program, results and data: specialties matching service 2019 appointment year. National Resident Matching Program, Washington, DC. 2019. Available from: https:// mk0nrmpcikgb8jxyd19h.kinstacdn.com/wp-content/uploads/2019/02/ Results-and-Data-SMS-2019.pdf. Accessed October 12, 2019, page 39.
23. National Resident Matching Program, results and data: specialties matching service 2019 appointment year. National Resident Matching Program, Washington, DC. 2019. Available from: https://mk0nrmp3oyqui6wqfm. kinstacdn.com/wp-content/uploads/2019/04/NRMP-Results-and-Data2019 04112019_final.pdf. Accessed October 21, 2019, page 4.

24. National Resident Matching Program, results and data: 2013 main residency match ${ }^{\circledR}$. National Resident Matching Program, Washington, DC. 2013. Available from: http://www.nrmp.org/wp-con tent/uploads/2013/08/resultsanddata2013.pdf. Accessed October 12, 2019.

25. National Resident Matching Program, results and data: 2014 main residency match ${ }^{\circledR}$. National Resident Matching Program, Washington, DC. 2014. Available from: https:/www.nrmp.org/ wp-content/uploads/2014/04/Main-Match-Results-and-Data-2014. pdf. Accessed October 12, 2019.

26. National Resident Matching Program, results and data: 2011 main residency match. National Resident Matching Program, Washington, DC. 2011. Available from: http://www.nrmp.org/wp-content/uploads/ 2013/08/resultsanddata2011.pdf. Accessed October 12, 2019, page 3.

27. National Resident Matching Program, results and data: 2012 main residency match ${ }^{\mathrm{SM}}$. National Resident Matching Program, Washington, DC. 2012. Available from: http://www.nrmp.org/wp-con tent/uploads/2013/08/resultsanddata20121.pdf. Accessed October 12, 2019, page 3 .

28. National Resident Matching Program, results and data: 2015 main residency match ${ }^{\circledR}$. National Resident Matching Program, Washington, DC. 2015. Available from: http://www.nrmp.org/wpcontent/uploads/2015/05/Main-Match-Results-and-Data-2015_final. pdf. Accessed October 12, 2019, page 4
Advances in Medical Education and Practice

\section{Publish your work in this journal}

Advances in Medical Education and Practice is an international, peerreviewed, open access journal that aims to present and publish research on Medical Education covering medical, dental, nursing and allied health care professional education. The journal covers undergraduate education, postgraduate training and continuing medical education including emerging trends and innovative models linking education, research, and health care services. The manuscript management system is completely online and includes a very quick and fair peer-review system. Visit http://www.dovepress.com/testimonials.php to read real quotes from published authors. 